\title{
PENGARUH LINGKUNGAN KERJA DAN KEPEMIMPINAN TERHADAP KEPUASAN KERJA KARYAWAN DI PT. LAHAN REZEKI KABUPATEN KUNINGAN
}

\author{
Ariq Saeful Rochmaan Nurhidayat ${ }^{1}$, Sandi Nasrudin Wibowo ${ }^{2}$ \\ Universitas Swadaya Gunung Jati Cirebon (UGJ) ${ }^{\mathbf{1 , 2}}$ \\ sandi.nwibowo@ugj.ac.id
}

\begin{abstract}
ABSTRAK
Penelitian ini bertujuan untuk mengetahui pengaruh lingkungan kerja dan kepemimpinan terhadap kepuasan kerja karyawan di PT. Lahan Rezeki Kabupaten Kuningan. Populasi dalam penelitian ini adalah semua karyawan di PT. Lahan Rezeki. Teknik pengambilan sampel dalam penelitian ini menggunakan sampel jenuh. Sampel dalam penelitian ini sebanyak 55 orang responden. Metode dalam pengumpulan data ini menggunakan kuesioner, sedangkan metode dalam penelitian ini menggunakan analisis regresi linear berganda. Hasil penelitian ini menunjukan bahwa lingkungan kerja berpengaruh positif dan signifikan. Hal ini dibuktikan dengan nilai p-value (sig) $<0,05$ yaitu $0,040<0,05$ dan nilai thitung > ttabel yaitu 2,107 > 2,0057 sehingga dapat disimpulkan bahwa variabel berpengaruh positif dan signifikan terhadap kepuasan kerja karyawan. Kepemimpinan berpengaruh positif dan signifikan terhadap kepuasan kerja karyawan. Hal ini dibuktikan dengan nilai p-value (sig) $<0,05$ yaitu $0,000<$ 0,05 dan nilai thitung > ttabel yaitu 9,267>2,0057 sehingga dapat disimpulkan bahwa variabel berpengaruh positif dan signifikan terhadap kepuasan kerja karyawan. Lingkungan kerja dan kepemimpinan berprngaruh positif dan signifikan terhadap kepuasan kerja karyawan. Hal ini dibuktikan dengan nilai p-value (sig) $<0,05$ yaitu $0,000<0,05$ dan nilai fhitung $>$ ftabel yaitu 44,565 $>3,28$ sehingga dapat disimpulkan bahwa kedua variabel berpengaruh positif dan signifikan terhadap kepuasan kerja karyawan..
\end{abstract}

Kata-kata Kunci: lingkungan kerja; kepemimpinan; kepuasan kerja karyawan

\section{The Influence of Work Environment and Leadership on Employee Job Satisfaction at PT.Lahan Rezeki Kuningan Regency}

\begin{abstract}
This study aims to determine the effect of work environment and leadership on employee job satisfaction at PT.Lahan Rezeki Kuningan Regency. The population in this study were all employees at PT. Sustenance Land. The sampling technique in this study used a saturated sample. The sample in this study were 55 respondents. The method in collecting this data uses a questionnaire, while the method in this study uses multiple linear regression analysis. The results of this study indicate that the work environment has a positive and significant effect. This is evidenced by the value of p-value (sig) $<0.05$, namely $0.040<0.05$ and the value of tcount $>$ ttable which is 2.107>2.0057 so it can be concluded that the variable has a positive and significant effect on employee job satisfaction. Leadership has a positive and significant effect on employee job satisfaction. This is evidenced by the value of p-value (sig) $<0.05$, namely $0.000<0.05$ and the value of tcount $>$ ttable which is 9.267> 2.0057 so it can be concluded that the variable has a positive and significant effect on employee job satisfaction. The work environment and leadership have a positive and significant impact on employee job satisfaction. This is evidenced by the value of p-value (sig) $<0.05$, namely $0.000<0.05$ and the value of fcount > ftable which is $44.565>3.28$, so it can be concluded that both variables have a positive and significant effect on employee job satisfaction.
\end{abstract}

Keywords: work environment ; leadership ; employee job satisfaction 


\section{PENDAHULUAN}

\section{Latar Belakang Penelitian}

Perkembangan bisnis saat ini sangat pesat sehingga persaingan dalam dunia bisnis semakin ketat. Oleh karena itu, perusahaan dituntut harus meningkatkan kinerja perusahaan dan sumber daya manusia yang dimiliki agar peusahan tetap bertahan dalam menghadapi persaingan dengan perusahaan lain. Sumber daya manusia merupakan suatu hal yang sangat penting dan harus dimiliki dalam upaya mencapai tujuan organisasi atau perusahaan. Untuk mencapai hal tersebut, maka hal penting yang patut diperhatikan dalam pemeliharaan hubungan tersebut antara lain adalah kepuasan kerja pegawainya.

Kepuasan kerja pegawai berhubungan erat dengan kinerja pegawai. Seseorang yang puas dalam pekerjaannya akan memiliki motivasi, komitmen pada organisasi yang tinggi sehingga akan terus memperbaiki kinerja mereka. Dalam menciptakan kepuasan kerja maka dibutuhkan lingkungan kerja yang nyaman. Penyediaan lingkungan kerja secara nyaman akan mampu memberikan kepuasan kepada karyawan terhadap pekerjaan yang dilakukan.

Disamping itu, keberhasilan perusahaan dalam mencapai tujuannya tidak dapat dilepaskan dari peran pemimpinnya. Dalam suatu perusahaan, seorang pemimpin bukan semata-mata sebagai objek dalam pencapaian tujuan, tetapi sekaligus menjadi subjek atau pelaku. Upaya yang dapat dilakukaan oleh seorang pemimpin adalah mengarahkan, meningkatkan, dan menggerakan potensi diri dan anggotanya secara bersama-sama memfokuskan kegiatannya demi mencapai keberhasilan suatu perusahaan.

PT. Lahan Rezeki merupakan sebuah perusahaan yang bergerak dibidang usaha pengolahan bawang mentah menjadi bawang goreng. Hasil dari pengolahan bawang tersebut di kirim langsung ke perusahaan Indofood yang ada di luar kota seperti Surabaya, Semarang, dan Jakarta. Perusahaan ini terletak di Jl. Siliwangi, Kecamatan Kramatmulya, Kabupaten Kuningan.

Berdasarkan wawancara dengan beberapa karyawan bahwa lingkungan kerja disini yaitu kurangnya penerangan pada gudang pengemasan, penyimpanan bahan baku yang mash jauh dari jangkauan karyawan, kerja sama antar rekan kerja di perusahaan masih belum maksimal, terlihat dari masih adanya karyawan yang lebih suka bekerja secara individu daripada harus bekerja sama, suka adanya konflik antar karyawan dalam bekerja dan belum tersedianya fasilitas seperti kantin di perusahaan. 
Selain itu, peneliti juga memperoleh fenomena pada kepemimpinan di PT. Lahan Rezeki bahwa kepemimpinan dalam PT. Lahan Rezeki ini yaitu seorang pemimpin tidak selalu memberikan bimbingan, arahan, dan dorongan kepada karyawannya dalam bekerja. Kurangnya perhatian seorang pemimpin pada karyawannya dan jika ada keluhan yang dirasakan oleh karyawan dalam pekerjaannya, seorang pemimpin tidak begitu menanggapinya.

Hal ini juga dapat dilihat dari beberapa penelitian yang telah dilakukan oleh (Rini Astuti, Iverizkinawati, 2018) yang berjudul pengaruh kepemimpinan dan lingkungan kerja terhadap kepuasan keja karyawan pada PT. Sarana Agro Nusantara Medan. Hasil penelitian menunjukan bahwa kepemimpinan dan lingkungan kerja mempunyai pengaruh signifikan terhadap kepuasan kerja karyawan.

\section{Rumusan Masalah}

1) Apakah lingkungan kerja berpengaruh terhadap kepuasan kerja karyawan di PT. Lahan Rezeki

2) Apakah kepemimpinan berpengaruh terhadap kepuasan kerja karyawan di PT. Lahan Rezeki

3) Apakah lingkungan kerja dan kepemimpinan secara bersama-sama berpengaruh terhadap kepuasan kerja karyawan di PT. Lahan Rezeki

\section{Tujuan Penelitian}

1) Menganalisis pengaruh lingkungan kerja terhadap kepuasan kerja karyawan di PT. Lahan Rezeki.

2) Menganalisis pengaruh kepemimpinan terhadap kepuasan kerja karyawan di PT. Lahan Rezeki.

3) Menganalisis pengaruh lingkungan kerja dan kepemimpinan secara bersama-sama terhadap kepuasan kerja karyawan di PT. Lahan Rezeki.

\section{KAJIAN LITERATUR}

\section{Lingkungan Kerja}

Setiap organisasi baik yang bersekala besar, menengah, maupun kecil, semuanya akan berinteraksi dengan lingkungan dimana organisasi atau perusahaan tersebut berada. Lingkungan itu sendiri mengalami perubahan-perubahan sehingga organisasi atau perusahaan yang bisa bertahan hidup adalah organisasi yang bisa menyesuaikan diri dengan perubahan lingkungan

Lingkungan Kerja menurut Sedarmayanti (dalam Setiana 2019:152) yaitu keseluruhan alat perkakas dan bahan yang dihadapi lingkungan sekitarnya, dimana seseorang bekerja, metode kerjanya dan pengaturan kerjanya baik sebagai perseorang maupun sebagai kelompok.

Menurut Sedarmayanti (dalam Setiana 2019:152) mengatakan bahwa jenis lingkungan kerja terbagi menjadi dua macam, yakni : 
1) Lingkungan kerja fisik

lingkungan kerja fisik adalah seluruh keadaan yang berbentuk fisik dan hal ini ada di sekitar wilayah tempat kerja dan bisa memberikan pengaruh terhadap pekerja/pegawai, dengan secara langsung dan atau secara tidak langsung.

2) Lingkungan kerja non fisik

lingkungan kerja non fisik adalah seluruh situasi yang terjadi dan memiliki keterkaitan dengan hubungan kerja, baik itu dengan atasan ataupun sesama pegawai/pekerja dan bawahan.

\section{Kepemimpinan}

Kepemimpinan memegang peran penting dalam memahami perilaku kelompok karena biasanya pemimpin yang mengarahkan kita menuju tujuan. Untuk membangun suatu organisasi agar terbentuk model perilaku organisasi yang berkarakter maka semua itu pada prinsipnya harus dimulai dari pembentukan karakter pimpinan terlebih dahulu.

Kepemimpinan menurut Peter G. Northouse (2018:5) mengemukakan bahwa Kepemimpinan adalah proses di mana individu memengaruhi sekelompok individu untuk mencapai tujuan bersama.

Menurut Peter G. Northouse (2018:13) terdapat 3 dimensi, yaitu:

1) Menentukan arah

2) Menyatukan orang-orang

\section{Kepuasan Kerja}

Kepuasan kerja pegawai adalah suatu fenomena yang perlu dicermati oleh pimpinan organisasi. kepuasan kerja pegawai berhubungan erat dengan kinerja pegawai. Seorang yang puas dalam pekerjaannya akan memiliki motivasi, komitmen pad organisasi dan partisipasi kerja yang tinggi sehingga akan terus memperbaiki kinerja mereka.

kepuasan kerja menurut Sutrisno (2020:75) yaitu perasaan senang atau seneng pekerja dalam memandang dan menjalankan pekerjaannya. Menurut Sutrisno (2020:80) bahwa ada 4 faktor yang mempengaruhi kepuasan kerja yaitu:

1) Faktor Psikologis

Merupakan faktor yang berhubungan dengan kejiwaan karyawan, yang meliputi minat, ketentraman dalam bekerja, sikap terhadap kerja, bakat dan keterampilan.

2) Faktor Sosial

Merupakan faktor yang berhubungan dengan interaksi sosial antar karyawan maupun karyawan dengan atasan.

3) Faktor Fisik

Merupakan faktor yang berhubungan kondisi fikis karyawan, meliputi jenis pekerjaan, pengaturan waktu dan waktu istirahat, perlengkapan kerja, keadaan ruangan, suhu, penerangan, Memotivasi dan memberi inspirasi 
pertukaran udara, kondisi kesehatan karyawan, umur, dan sebagainya.

4) Faktor Finansial

Merupakan faktor yang berhubungan dengan jaminan serta kesejahteraan karyawan, yang meliputi sistem dan besarnya gaji, jaminan sosial, macammacam tunjangan, fasilitas yang diberikan, promosi dan sebagainya.

\section{METODE PENELITIAN}

\section{Jenis Penelitian}

Jenis penelitian yang akan digunakan adalah jenis penelitian asosiatif. penelitian asosiatif menurut Sugiyono (2019:65) yaitu suatu rumusan masalah penelitian yang bersifat menanyakan hubungan antara dua variabel atau lebih.

\section{Populasi dan Sampel}

bahy $\begin{array}{ll}\text { Sugivono }(2019: 126) & \text { mengatakan } \\ \mathrm{Y}=\mathrm{a}+\mathrm{b}_{1} \mathrm{X}_{1}+\mathrm{b}_{2} \mathrm{X}_{2} & \text { ralisasi }\end{array}$ yang terdiri atas objek atau subjek yang mempunyai kuantitas dan karakteristik tertentu yang ditetapkan oleh peneliti untuk dipelajari dan kemudian ditarik kesimpulannya. Populasi dalam penelitian ini adalah Karyawan PT. Lahan Rezeki.

Sugiyono (2019:127) menyatakan bahwa sampel adalah bagian dari jumlah dan karakteristik yang dimiliki oleh populasi tersebut. Penelitian sampel dalam penelitian ini menggunakan teknik sampling nonprobability sampling yaitu sampling jenuh. Sampel dalam penelitian ini adalah sebesar 55 orang karyawan dimana jumlah populasi dijadikan sampel.

\section{Teknik Pengumpulan Data}

1) Studi Lapangan
a. Wawancara
b. Kuesioner

2) Studi Pustaka
a. Data primer
b. Data sekunder

\section{Metode Analisis Data}

\section{Regresi Linear Berganda}

Analisis regresi berganda digunaan untuk mengetahui pengaruh lingkungan kerja dan kepemimpinan secara simultan terhadap Kepuasan kerja Karyawan. Analisis regresi berganda akan dilakukan bila jumlah variabel indpendennya lebih dari dua.

\section{Sumber: Sugiyono (2017:192)}

\section{Koefisien Determinasi}

Koefisien Determinasi $\left(\mathrm{R}^{2}\right)$ pada intinya digunakan untuk mengukur seberapa jauh kemampuan model dalam menerangkan variabel terikat (dependen) (Ghozali, 2018:95). Pada model regresi linear berganda ini akan dilihat besarnya kontribusi untuk variabel indepanden terhadap variabel dependen dengan melihat besarnya koefisien determinasi totalnya.

\section{Uji T}


Uji t dimaksudkan untuk menguji signifikansi koefisien regresi antara variabel-variabel bebas terhadap variabel terikat secara individu.

Jika $t$ hitung $>\mathrm{t}$ tabel maka Ho ditolak artinya variabel independen berpengaruh signifikan terhadap variabel dependen Jika t hitung $<$ t tabel maka Ho diterima artinya variabel independen tidak berpengaruh signifikan terhadap variabel dependen

\section{Uji F}

Uji f dapat digunakan untuk menguji signifikasi pengaruh variabel bebas secara simultan terhadap variabel terikat. Jika $F$ hitung > F tabel maka Ho ditolak artinya variabel independen berpengaruh signifikan terhadap variabel dependen. Jika F hitung < F tabel maka Ho diterima artinya variabel independen tidak berpengaruh signifikan terhadap variabel dependen.

\section{HASIL DAN PEMBAHASAN}

\section{Uji Regresi Linear Berganda}

Analisis Regresi Berganda dilakukan untuk mengetahui besarnya pengaruh dari beberapa variabel independent secara bersamaan terhadap variabel dependen, dalam penelitian ini adalah variabel Lingkungan Kerja $\left(\mathrm{X}_{1}\right)$ dan Kepemimpinan $\left(\mathrm{X}_{2}\right)$ terhadap Kepuasan Kerja (Y), berikut ini hasil ditunjukan dengan tabel sebagai berikut:
Tabel 1

Hasil Analisis Regresi Linear Berganda $\left(\mathbf{X}_{\mathbf{1}}\right),\left(\mathbf{X}_{\mathbf{2}}\right),(\mathbf{Y})$

\begin{tabular}{|c|c|c|c|c|c|}
\hline \multicolumn{6}{|c|}{ Coefficients $^{\mathrm{a}}$} \\
\hline \multirow[b]{2}{*}{ Model } & \multicolumn{2}{|c|}{$\begin{array}{l}\text { Unstandardized } \\
\text { Coefficients }\end{array}$} & $\begin{array}{c}\text { Stan } \\
\text { dardi } \\
\text { zed } \\
\text { Coef } \\
\text { ficien } \\
\text { ts } \\
\end{array}$ & & \\
\hline & B & $\begin{array}{l}\text { Std. } \\
\text { Error }\end{array}$ & Beta & $t$ & Sig. \\
\hline $\begin{array}{ll}1 & \text { (Cons } \\
& \text { tant) }\end{array}$ & 1.915 & 11.570 & & .166 & .869 \\
\hline $\begin{array}{l}\text { Lingk } \\
\text { ungan } \\
\text { Kerja }\end{array}$ & .119 & .056 & .177 & 2.107 & .040 \\
\hline $\begin{array}{l}\text { Kepe } \\
\text { mimpi } \\
\text { nan }\end{array}$ & 1.373 & .148 & .780 & 9.267 & .000 \\
\hline
\end{tabular}

a. Dependent Variable: Kepuasan Kerja

Sumber: Hasil output Spss.23 for windows

Berdasarkan tabel diatas nilai konstanta sebesar 1,915 sedangkan nilai Lingkungan kerja 0,119 dan nilai Kepemimpinan 1,373 jika dapat diketahui persamaan regresi yaitu:

$$
Y=1,915+0,119 X_{1}+1,373 X_{2}
$$

Persamaan dari regresi linear berganda diatas dapat dijelaskan sebagai berikut:

1) Nilai konstanta adalah sebesar 1,915 . Hal ini berarti bahwa lingkungan kerja dan kepemimpinan nilainya 0 , maka kepuasan kerja 1,915.

2) Koefisien regresi variabel lingkungan kerja sebesar 0,119 yang berarti menunjukan arah hubungan yang positif (searah) antara lingkungan kerja dan kepuasan kerja. Hal ini bahwa setiap kenaikan variabel lingkungan 
kerja sebesar 1 maka kepuasan kerja akan naik 0,119

3) Koefisien regresi variabel kepemimpinan sebesar 1,373 yang berarti menunjukan arah hubungan yang positif (searah) antara kepemimpinan dan kepuasan kerja. Hal ini bahwa setiap kenaikan variabel lingkungan kerja sebesar 1 maka kepuasan kerja akan naik 1,373.

\section{Koefisien Determinasi}

Koefisien Determinasi $\left(\mathrm{R}^{2}\right)$ pada intinya digunakan untuk mengukur seberapa jauh kemampuan model dalam menerangkan variabel terikat (dependen) (Ghozali, 2018:95). Pada model regresi linear berganda ini akan dilihat besarnya kontribusi untuk variabel indepanden terhadap variabel dependen dengan melihat besarnya koefisien determinasi totalnya.

\section{Coefficients $^{a}$}

\begin{tabular}{|c|c|c|c|c|c|}
\hline \multirow[b]{2}{*}{ Model } & \multicolumn{2}{|c|}{$\begin{array}{l}\text { Unstandardized } \\
\text { Coefficients }\end{array}$} & \multirow{2}{*}{$\begin{array}{l}\text { Stan } \\
\text { dardi } \\
\text { zed } \\
\text { Coef } \\
\text { ficien } \\
\text { ts } \\
\text { Beta }\end{array}$} & \multirow[b]{2}{*}{$t$} & \multirow[b]{2}{*}{ Sig. } \\
\hline & $B$ & $\begin{array}{l}\text { Std. } \\
\text { Error }\end{array}$ & & & \\
\hline $\begin{array}{l}\text { (Constan } \\
\text { t) }\end{array}$ & 1.915 & 11.570 & & .166 & .869 \\
\hline $\begin{array}{l}\text { Lingkung } \\
\text { an Kerja }\end{array}$ & .119 & .056 & .177 & 2.107 & .040 \\
\hline $\begin{array}{l}\text { Kepemim } \\
\text { pinan }\end{array}$ & 1.373 & .148 & .780 & 9.267 & .000 \\
\hline
\end{tabular}

a. Dependent Variable: Kepuasan Kerja

Berikut ini hasil koefisien determinasi ditunjukan dengan tabel sebagai berikut :

Tabel 2

Koefisien Determinasi $\left(\mathbf{R}^{2}\right)$

Model Summary

\begin{tabular}{|l|c|c|c|c|}
\hline Model & $\mathrm{R}$ & $\begin{array}{c}\mathrm{R} \\
\mathrm{e}\end{array}$ & $\begin{array}{c}\text { Adjusted R } \\
\text { Square }\end{array}$ & $\begin{array}{c}\text { Std. Error of the } \\
\text { Estimate }\end{array}$ \\
\hline 1 & $\begin{array}{r}.795 \\
\mathrm{a}\end{array}$ & .632 & .617 & 5.795 \\
\hline
\end{tabular}

a. Predictors: (Constant), Kepemimpinan, Lingkungan Kerja

Berdasarkan tabel di atas menunjukan nilai Adjusted $R$ Square sebesar 0,617 sehingga persentase pengaruh lingkungan kerja dan kepemimpinan secara bersama sama terhadap kepuasan kerja karyawan yaitu sebesar $61,7 \%$ dan sisanya $38,3 \%$ kepuasan kerja karyawan dipengaruhi variabel lain diluar variabel yang diteliti.

\section{Uji T}

Uji t dilakukan untuk menguji apakah tiap-tiap variabel independen memiliki pengaruh yang signifikan terhadap variabel dependen. Uji parsial dapat diketahui dengan menggunakan perbandingan $t_{\text {hitung }}>$ $t_{\text {tabel }}$ maka hipotesis penelitian secara pasrsial diterima (signifikan) dan jika thitung $<t_{\text {tabel }}$ maka hipotesis penelitian secara parsial ditolak (tidak signifikan). Pengujian secara parsial mengenai variabel lingkungan kerja terhadap kepuasan kerja karyawan dapat diajukan hipotesis pertama sebagai berikut:

\section{Tabel 3 \\ Hasil Uji t}

\section{Sumber: Hasil output Spss.23 for}

\section{windows}

Berdasarkan hasil perhitungan pada tabel di atas untuk variabel lingkungan kerja diperoleh angka thitung $>$ tabel yaitu 2,107 > 
2,0057 dan nilai signifikansi $0,04<0,05$.

Nilai ttabel dapat diperoleh dari degree of freedom $(d f)=55-2=53$ pada taraf signifikansi 0,05 (uji dua sisi)sebesar 2,0057. Maka bisa ditarik kesimpulan bahwa terdapat pengaruh yang signifikan antara lingkungan kerja terhadap kepuasan kerja karyawan.

Berdasarkan hasil perhitungan pada tabel diatas untuk variabel kepemimpinan diperoleh angka thitung $>$ tabel yaitu 9,267 > 2,0057 dan nilai signifikansi 0,000<0,05. Nilai ttabel dapat diperoleh dari degree of freedom $(d f)=55-2=53$ pada taraf signifikansi 0,05 (uji dua sisi) sebesar 2,0057. Maka bisa ditarik kesimpulan bahwa terdapat pengaruh yang signifikan antara kepemimpinan terhadap kepuasan kerja karyawan di PT. Lahan Rezeki Kabupaten Kuningan.

\section{Uji F}

Pengujian ini untuk mengetahui pengaruh variabel independen secara bersama-sama terhadap variabel dependen. Apabila hasil uji $F_{\text {hitung }}>F_{\text {tabel }}$ berartivariabel independen signifikan untuk menjelaskan variabel dependen.

\section{Tabel 4}

\section{Hasil Uji F}

ANOVA $^{\mathrm{a}}$

\begin{tabular}{|r|c|c|c|c|c|}
\hline Model & $\begin{array}{c}\text { Sum of } \\
\text { Squares }\end{array}$ & Df & $\begin{array}{c}\text { Mean } \\
\text { Square }\end{array}$ & F & Sig. \\
\hline $1 \begin{array}{l}\text { Reg } \\
\text { ress } \\
\text { ion }\end{array}$ & 2993.117 & 2 & 1496.559 & 44.565 & $\begin{array}{r}.000 \\
\text { b }\end{array}$ \\
\hline
\end{tabular}

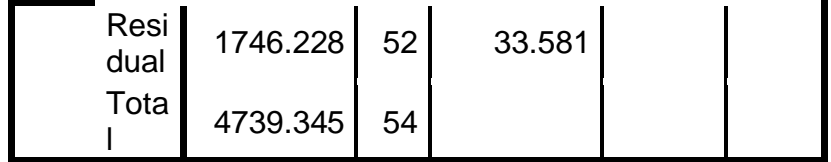

a. Dependent Variable: Kepuasan Kerja

b. Predictors: (Constant), Kepemimpinan, Lingkungan Kerja

Sumber: Hasil output Spss.23 for windows

Tabel di atas menunjukan Fhitung 44,565 > Ftabel 3,18 artinya signifikan, dengan nilai Ftabel dengan derajat kebebasan atau degree of freedom df 2 ( $\mathrm{n}-$ $\mathrm{k}-1)$ atau $55-2-1=52$ pada taraf signifikansi 0,05 (uji dua sisi) sebesar 3,18. Signifikan disini berarti H3 diterima. Artinya lingkungan kerja dan kepemimpinan secara bersama-sama atau secara simultan berpengauh terhadap kepuasan kerja karyawan di PT. Lahan Rezeki Kabupaten Kuningan.

\section{SIMPULAN}

Berdasarkan hasil penelitian dan hasil analisis data mengenai pengaruh lingkungan kerja dan kepemimpinan terhadap kepuasan kerja karyawan di PT. Lahan Rezeki Kabupaten Kuningann dengan melakukan pengujian atas tiga penelitian, maka dapat disimpulkan sebagai berikut:

a. Hasil pengujian variabel lingkungan kerja $\left(X_{1}\right)$ berpengaruh positif dan signifikan terhadap kepuasan kerja karyawan di PT. Lahan Rezeki Kabupaten Kuningan. Artinya 
dengan menciptakan lingkungan kerja yang aman, nyaman dan kondusif di dalam perusahaan maka akan menimbulkan rasa kepuasan kerja bagi karyawan.

b. Hasil pengujian variabel kepemimpinan $\left(\mathrm{X}_{2}\right)$ berpengaruh positif dan signifikan terhadap kepuasan kerja karyawan di PT. Lahan Rezeki Kabupaten Kuningan. Artinya dengan kepemimpinan yang selalu memperhatikan karyawannya maka akan menimbulkan rasa kepuasan kerja bagi karyawannya.

c. Hasil pengujian variabel lingkungan kerja $\left(\mathrm{X}_{1}\right)$ dan kepemimpinan $\left(\mathrm{X}_{2}\right)$ secara bersama-sama (simultan) berpengaruh positif dan signifikan terhadap kepuasan kerja karyawan di PT. Lahan Rezeki Kabupaten Kuningan. Artinya dengan menciptakan lingkungan kerja yang aman, nyaman dan kondusif di dalam perusahaan seperti adanya lampu penerangan di setiap ruangan dan selalu menjaga hubungan antar karyawan maupun dengan atasan akan mampu memberikan rasa kepuasan kerja bagi karyawan. Selain itu, seorang pemimpin harus memperhatikan karyawannya agar karyawan merasa puas dalam melakukan pekerjaannya

\section{DAFTAR PUSTAKA}

\section{Buku}

Sinambela, L. P. (2016). Manajemen Sumber Daya Manusia. Jakarta: PT. Bumi Aksara.

Afandi, P. (2018). MANAJEMEN SUMBER DAYA MANUSIA Teori, Konsep, dan Indikator. Yogyakarta: ZANAFA.

Ghozali, I. (2018). Aplikasi Analisis Multivariete Dengan Program IBM SPSS 23. Semarang: Undip.

Sedermayanti. (2016). SUMBER DAYA MANUSIA. Bandung: PT. Refika Aditama.

Sugiono. (2017). Metode Penelitian Kuantitatif, Kualitatif Dan $R \& D$. Bandung: CV. Alfabeta.

Umar, H. (2020). Metode Penelitian Untuk Skripsi Dan Tesis Bisnis. Jakarta: PT. RAJAGARAFINDO PERSADA.

Sugiono. (2019). METODE PENELITIAN KUANTITATIF KUALITATIF dan $R \& D$. Bandung: Alfabeta.

Sutrisno, E. (2020). MANAJEMEN SUMBER DAYA MANUSIA. Jakarta: KENCANA.

Setiana, A. R. (2019). Manajemen Sumber Daya Manusia. Bandung: MANGGU MAKMUR TANJUNG LESTARI.

Wibowo. (2017). PERILAKU DALAM ORGANISASI. Depok: PT RAJAGRAFINDO PERSADA. 
Mangkunegara, A. P. (2019). MANAJEMEN SUMBER DAYA MANUSIA PERUSAHAAN. Bandung: PT REMAJA ROSDAKARYA.

Northouse, P. G. (2018). KEPEMIMPINAN : Teori dan Praktik. Jakarta: PT Indeks.

EMRON EDISON, YOHNI ANWAR, I. K. (2018). MANAJEMEN SUMBER DAYA MANUSIA Strategi dan Perubahan dalam Rangka Meningkatkan Kinerja Pegawai dan Organisasi. Bandung: ALVABETA.

Handoko, T. H. (2016). MANAJEMEN. Yogyakarta: BPFE-YOGYAKARTA. Ernie Tisnawati Sule, K. S. (2019). Pengantar MANAJEMEN. Jakarta: PRENADAMEDIA GROUP.

\section{Jurnal}

Mindari, E. (2018). Pengaruh Kompensasi, Lingkungan Kerja Dan Kepemimpinan Terhadap Kepuasan Kerja Karyawan Pt. Bisma Hamirah Palembang. Jurnal Ecoment Global, $3(1)$, 35. https://doi.org/10.35908/jeg.v3i1.355 Kerja, P. L., Sdm, D. A. N. P., Kepuasan, T., Karyawan, K., Pln, P. T., Wilayah, P., Ekonomi, F., Manajemen, J., \& Ratulangi, U. S. (2018). Pengaruh Lingkungan Kerja, Pelatihan, Dan Pemberdayaan Sdm Terhadap Kepuasan Kerja Karyawan Pt. Pln Page | 94
(Persero) Wilayah Suluttenggo. Jurnal EMBA: Jurnal Riset Ekonomi, Manajemen, Bisnis Dan Akuntansi, $6(3)$, 1828-1837. https://doi.org/10.35794/emba.v6i3.20 665

Tamali, H., \& Munasip, A. (2019). Pengaruh Kompensasi, Kepemimpinan, Dan Lingkungan Kerja Terhadap Kepuasan Kerja Karyawan. Maneggio: Jurnal Ilmiah Magister Manajemen, 2(1), 55-68. https://doi.org/10.30596/maneggio.v2i 1.3403

Aruan, Q. S., \& Fakhri, M. (2015). Pengaruh Lingkungan Kerja Terhadap Kepuasan Kerja Karyawan Lapangan Departemen Grasberg Power Distribution PT. Freeport Indonesia. Modus, 27(2), 141-162. 